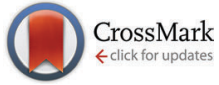

Cite this: Phys. Chem. Chem. Phys., 2014, 16, 18926

Received 22nd June 2014, Accepted 1st July 2014

DOI: $10.1039 / c 4 c p 02733 g$

www.rsc.org/pccp

\section{High voltage hybrid organic photovoltaics using a zinc oxide acceptor and a subphthalocyanine donort}

\author{
Chloe Argent Dearden, ${ }^{a}$ Marc Walker, ${ }^{\mathrm{b}}$ Nicola Beaumont, ${ }^{a}$ Ian Hancox, ${ }^{a}$ \\ Natalie K. Unsworth, ${ }^{a}$ Paul Sullivan, ${ }^{a}$ Chris F. McConville ${ }^{b}$ and Tim S. Jones*
}

\begin{abstract}
We demonstrate hybrid organic photovoltaic (HOPV) bilayer devices with very high open circuit voltages $\left(V_{\mathrm{OC}}\right)$ of $1.18 \mathrm{~V}$ based on a sol-gel processed zinc oxide $(\mathrm{ZnO})$ acceptor and a vacuum deposited boron subphthalocyanine chloride (SubPc) donor layer. X-ray photoelectron spectroscopy (XPS) and Kelvin Probe (KP) measurements of the $\mathrm{ZnO} / \mathrm{SubPc}$ interface show that the $\mathrm{ZnO}$ preparation conditions have a significant impact on the film composition and the electronic properties of the interface, in particular the work function and interface gap energy. Low temperature processing at $120{ }^{\circ} \mathrm{C}$ resulted in a $\mathrm{ZnO}$ work function of $3.20 \mathrm{eV}$ and the highest $V_{\mathrm{OC}}$ of $1.18 \mathrm{~V}$, a consequence of the increased interface gap energy.
\end{abstract}

\section{Introduction}

The field of organic photovoltaics (OPVs) has attracted considerable attention due to its potential for low cost solar energy conversion and its compatibility with non-rigid substrates. Organic materials allow many fabrication techniques to be employed that are simply not available for inorganic PVs, ${ }^{1}$ including the use of printable semiconductors and electrodes, ${ }^{2}$ spray coating, ${ }^{3}$ and spin coating, ${ }^{4}$ as well as the viability of large-scale, low cost production methods such as roll-to-roll processing. ${ }^{5}$ Improvements in the performance of OPVs have been achieved through the development of new absorbing materials, the use of interfacial layers, novel multi-stack architectures and through the effective use of dopants. ${ }^{6}$

The related research field of hybrid organic photovoltaics (HOPVs) has also attracted considerable recent attention. HOPVs typically combine the use of a p-type organic donor with an n-type inorganic acceptor such as a transition metal oxide (TMO). Zinc oxide ( $\mathrm{ZnO}$ ) has been the most commonly studied acceptor material and can be processed using a number of methods including electrodeposition, ${ }^{7}$ pulsed laser deposition, ${ }^{8}$ spray pyrolysis,,${ }^{9,10}$ and the sol-gel process. ${ }^{11}$ It has many appealing properties including high electron mobility, ${ }^{12}$ high transparency and the relative ease of fine tuning its morphological properties. ${ }^{13}$ To date, $\mathrm{ZnO}$ has been used in

\footnotetext{
${ }^{a}$ Department of Chemistry, University of Warwick, Coventry, CV4 7AL, UK. E-mail:T.S.Jones@warwick.ac.uk

${ }^{b}$ Department of Physics, University of Warwick, Coventry, CV4 7AL, UK $\dagger$ Electronic supplementary information (ESI) available: XPS survey scan and C 1s of the $\mathrm{ZnO}$ thin film processed at $120^{\circ} \mathrm{C}$ and $160^{\circ} \mathrm{C}$. See DOI: $10.1039 / \mathrm{c} 4 \mathrm{cp} 02733 \mathrm{~g}$
}

HOPV devices primarily as an electron-extracting layer providing ohmic contact with commonly used fullerene-based acceptors and thereby improving charge collection, ${ }^{14,15}$ however it has also been used as a direct replacement of the fullerene acceptor. ${ }^{16}$

The tunability of the $\mathrm{ZnO}$ conduction band (CB) also makes it an attractive material for HOPV applications, in particular as a means of enhancing the interface gap energy $\left(I_{g}\right)$ when combined with different organic donors; $I_{g}$ being the difference between the highest occupied molecular orbital (HOMO) of the donor and the lowest unoccupied molecular orbital (LUMO) of the acceptor. The $I_{\mathrm{g}}$ is known to be significant in the field of OPVs as the maximum achievable open circuit voltage $\left(V_{\mathrm{OC}}\right)$ of the cell can be predicted from the $I_{\mathrm{g}}$ minus any losses specific to each device due to thermodynamic and dissociation losses, band bending, energy losses at the contacts and recombination. ${ }^{17-20}$ For the most commonly used organic acceptor material, $\mathrm{C}_{60}$, one of the limitations is the poor $V_{\mathrm{OC}}$ that is achieved with a significant number of organic donor materials due to the deep lying LUMO level $(\sim 4.5 \mathrm{eV})$, and therefore the associated losses as a result of an excessively large energy offset $\left(\Delta_{\text {LUMO }}\right){ }^{21,22}$ Therefore, despite $\mathrm{C}_{60}$ functioning as an efficient acceptor material, there is the opportunity of improving the $V_{\mathrm{OC}}$ further by exploiting other material combinations that increase $I_{\mathrm{g}}$.

The simplest HOPV architecture is a planar bilayer structure with a single absorbing organic donor. If in analogy with OPV devices, it is assumed that $I_{\mathrm{g}}$ is directly related to the $V_{\mathrm{OC}}$ of the device, tuning the energy levels of the metal oxide and combining with different organic donors could result in significant improvements in the $V_{\mathrm{OC}}$. Ferreria et al. investigated two $\mathrm{ZnO}$ deposition methods, a sol-gel derived $\mathrm{ZnO}$ layer and the formation of $\mathrm{ZnO}$ nanoparticles synthesised in methanol. ${ }^{23}$ 
In a simple bilayer device with the polymeric donor poly(3-hexylthiophene) (P3HT), the $V_{\text {OC }}$ was increased from $0.4 \mathrm{~V}$ to $0.6 \mathrm{~V}$ simply by replacing the $\mathrm{ZnO}$ sol-gel layer with $\mathrm{ZnO}$ nanoparticles. This was attributed to the increase in $\mathrm{ZnO}$ band gap resulting in a larger $I_{\mathrm{g}}$. The substitution of polymers in HOPVs with evaporated organic small molecule semiconductors is an area that has received very little attention. ${ }^{24,25}$ One particular benefit is that it allows the controlled growth of very thin layers of the organic material, allowing the interface properties to be probed in a much more systematic way in order to explore the impact of the inorganic/organic junction on device performance. There have been a limited number of studies investigating TMO/organic small molecule interfaces with reported HOPV performances considerably lower than that of TMO/polymer cells. ${ }^{16}$ For example, in a recent study by Izaki et al. a hybrid phthalocyanine/ZnO buffer/n-type ZnO HOPV device resulted in a poor $V_{\mathrm{OC}}$ of $0.31 \mathrm{~V}$ and a power conversion efficiency (PCE) of just $1.6 \times 10^{-3} \% .^{26}$

In this paper, we show how the combination of a sol-gel processed $\mathrm{ZnO}$ layer with the small molecule organic semiconductor, boron subphthalocyanine chloride (SubPc), results in planar bilayer HOPV cells demonstrating very high open-circuit voltages. X-ray photoelectron spectroscopy (XPS) and Kelvin Probe (KP) measurements of the $\mathrm{ZnO} / \mathrm{SubPc}$ interface show that the $\mathrm{ZnO}$ preparation conditions have a significant impact on the composition of the layers and the electronic properties of the interface, most notably the work function and interface gap energy, and careful optimisation leads to a high $V_{\mathrm{OC}}$ of $1.18 \mathrm{~V}$ and a respectable PCE of $0.47 \%$, values much higher than those previously reported for similar device architectures.

\section{Experimental details}

ZnO thin films were fabricated on either pre-patterned ITO coated glass substrates (Thin Film Devices, $145 \mathrm{~nm}$ ITO thickness) or quartz substrates after a four-stage cleaning process and exposure to UV/ozone. A thin film of $\mathrm{ZnO}(\sim 45 \mathrm{~nm})$ was spin coated from a $0.25 \mathrm{M}$ precursor solution containing acetone (VWR, 99.9\%), zinc acetate (Aldrich, 99.99\%) and 2-amino ethanol (Aldrich, 99.5\%) which were used as the solvent, solute and chelating agent respectively. This solution was stirred for 1 hour prior to spin coating. The films were treated at two different annealing temperatures, $120{ }^{\circ} \mathrm{C}\left(\mathrm{ZnO}_{120^{\circ}} \mathrm{C}\right)$ and $160{ }^{\circ} \mathrm{C}\left(\mathrm{ZnO}_{160^{\circ} \mathrm{C}}\right)$, for 1 hour in air to allow conversion to $\mathrm{ZnO}$. Atomic force microscopy (AFM) images were obtained using an Asylum Research MFP-3D (Santa Barbara, USA) in AC mode. The MFP-3D was fitted with an ORCA integrated tip-holder and current preamplifier (20 nA) for conductive atomic force microscopy (C-AFM) measurements. Both the topography and current distribution images were obtained simultaneously using $\mathrm{Au} / \mathrm{Cr}$ coated cantilevers (Olympus TR400PB, tip radius $<40 \mathrm{~nm}$, spring constant $0.06 \mathrm{~N} \mathrm{~m}^{-1}$ ). To accurately determine the optical band gap using the method for non-crystalline semiconductors $^{27,28}$ thin films deposited onto a quartz substrate were analysed by UV/vis electronic absorption spectroscopy using a Perkin Elmer Lambda 25 spectrophotometer.

Further analysis of the ITO/ZnO films was performed using XPS. The measurements were taken ex situ after loading into an ultra-high vacuum system with a base pressure of $\sim 2 \times$ $10^{-11}$ mbar. XPS measurements were recorded using a monochromated X-ray $\mathrm{Al} \mathrm{K}_{\alpha}$ source (Omicron XM 1000, $h v=$ $1486.6 \mathrm{eV}$ ) and detected using an Omicron Sphera electron analyser at a take-off angle of $90^{\circ}$. A pass energy of $10 \mathrm{eV}$ was employed for both core levels and VB (resolution $=0.47 \mathrm{eV}$ ). All spectral features were referenced to the $\mathrm{C} 1 \mathrm{~s}$ peak $(284.6 \mathrm{eV})$ and fitted using Lorentzian asymmetric lineshapes and GaussianLorentzian lineshapes for zinc and oxygen respectively, both using a Shirley background. ${ }^{29} \mathrm{KP}$ measurements were used to determine the surface work function under a nitrogen atmosphere and referenced against freshly cleaved HOPG.

For device fabrication, SubPc (Lumtec 99\%, $15 \mathrm{~nm}$ ) and molybdenum oxide $\left(\mathrm{MoO}_{x}\right.$ Aldrich 99.99\%, $\left.15 \mathrm{~nm}\right)$ were vapour deposited onto the prepared $\mathrm{ZnO}$ films, followed by an aluminium (Al) top electrode through a shadow mask to give an active area of $0.16 \mathrm{~cm}^{2}$ using a Kurt J. Lesker Spectros system. All devices were tested under a nitrogen atmosphere in a sealed sample holder. Current density-voltage $(J-V)$ measurements were recorded using a Keithley 2400 sourcemeter with AM1.5G solar irradiation simulated with a Newport Oriel solar simulator

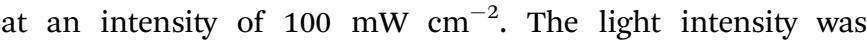
calibrated with a Fraunhofer calibrated silicon photodiode (PV Measurements Inc.) with a KG-5 filter. EQE measurements were obtained using light from a Sciencetech Xe arc lamp solar simulator and a computer controlled PTI monochromator. The mechanically chopped, monochromatic light intensity was calibrated with a Si photodiode (818UV, Newport) as a reference cell. The current measurement was performed with a current-voltage amplifier (Femto DHPCA-100) and lock-in amplifier (Stanford Research Systems SR 830 DSP).

\section{Results}

C-AFM was used to study the effect the processing temperature has on the surface conductivity of the $\mathrm{ZnO}$ thin films. Fig. 1 shows simultaneously obtained topography images [a-b], current distribution maps $[\mathrm{c}-\mathrm{d}]$ and histograms showing the corresponding current distributions $[\mathrm{e}-\mathrm{d}]$ for $\mathrm{ZnO}_{120^{\circ} \mathrm{C}}$ and $\mathrm{ZnO}_{160^{\circ} \mathrm{C}}$. The $\mathrm{ZnO}_{120^{\circ} \mathrm{C}}$ film has a surface roughness of $0.90 \mathrm{~nm}$, whereas $\mathrm{ZnO}_{160^{\circ} \mathrm{C}}$ has a slightly higher surface roughness of $1.95 \mathrm{~nm}$. The current distribution maps were acquired whilst applying a $6 \mathrm{~V}$ bias, indicating a distinct difference in the surface currents obtained by varying film preparation conditions. The average current for $\mathrm{ZnO}_{120^{\circ} \mathrm{C}}$ was $63 \mathrm{pA}$, significantly smaller than the average current of $1.2 \mathrm{nA}$ obtained for $\mathrm{ZnO}_{160^{\circ} \mathrm{C}}$ under the same conditions. The differences in surface conductivity are likely to be due to different phases of the $\mathrm{ZnO}$ layer which influences the currents expected and the interaction between the tip and the surface. ${ }^{30}$ 

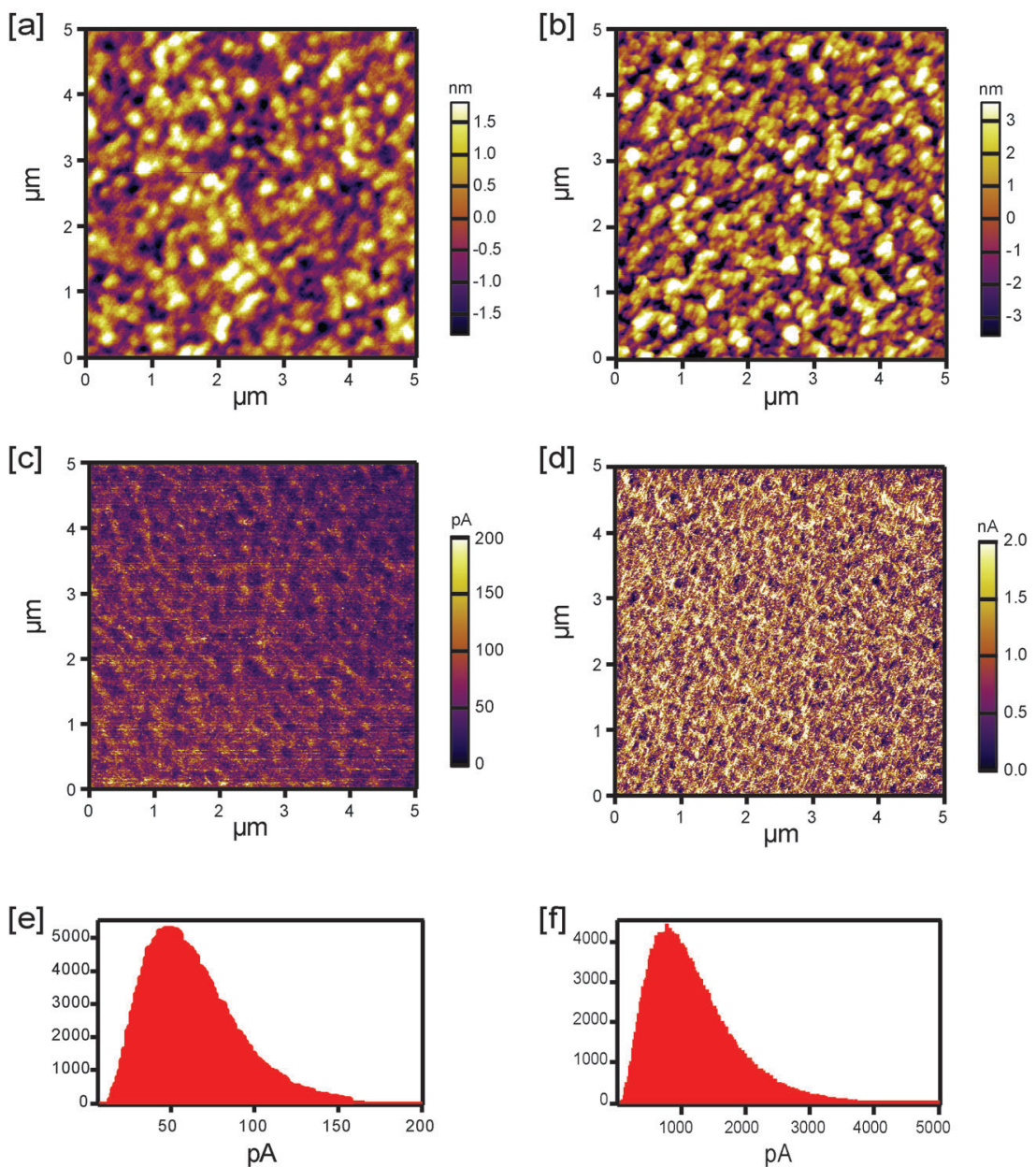

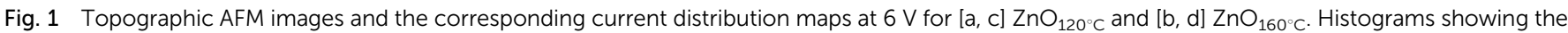
current distributions are also shown for [e] $\mathrm{ZnO}_{120^{\circ} \mathrm{C}}$ and [f] $\mathrm{ZnO}_{160^{\circ} \mathrm{C}}$.
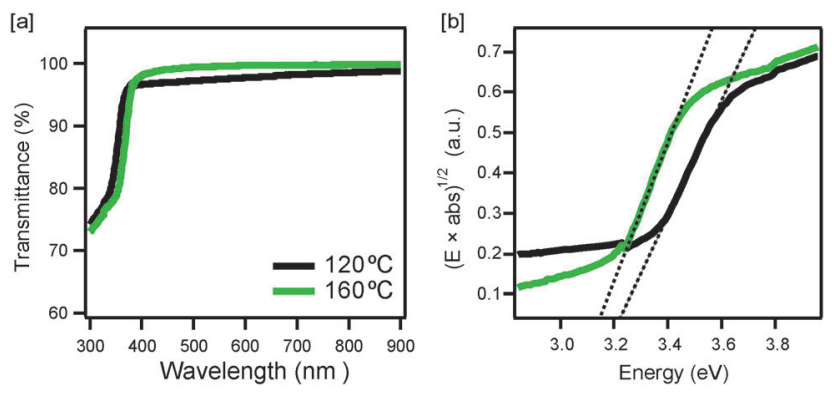

Fig. 2 [a] Transmittance data for a $\mathrm{ZnO}$ thin film spin-coated onto a quartz substrate against a quartz background for $\mathrm{ZnO}_{120^{\circ} \mathrm{C}}$ (black solid line) and $\mathrm{ZnO}_{160^{\circ} \mathrm{C}}$ (green solid line). [b] Determination of the band gap, $E_{\mathrm{g}}$, by plotting $(E \times a b s)^{1 / 2}$ as a function of energy $(\mathrm{eV})$ and determining the intercept with the energy axis (shown with the dotted lines).

The transmittance characteristics of the two $\mathrm{ZnO}$ films are summarised in Fig. 2. For both processing temperatures the films exhibit a high transmittance of $>95 \%$ across the visible and nearinfrared range (400-900 $\mathrm{nm}$ ). The band gaps were calculated from the absorption profiles by the method developed for non-crystalline semiconductors, ${ }^{27,28}$ with $\alpha \propto \frac{1}{E} \cdot\left(E-E_{\mathrm{g}}\right)^{2}$, giving a correlation between the energy of an incoming photon, $E$ and absorbance, $\alpha$. The band gap, $E_{\mathrm{g}}$, is then estimated from the intercept with the energy axis in a plot of $E(\mathrm{eV})$ versus $(E \times \alpha)^{1 / 2}$, (Fig. 2[b]) giving band gaps of $3.26 \mathrm{eV}$ and $3.15 \mathrm{eV}$, for $\mathrm{ZnO}_{120^{\circ} \mathrm{C}}$ and $\mathrm{ZnO}_{160^{\circ} \mathrm{C}}$ respectively. These values are consistent with the optical band gaps previously reported for $\mathrm{ZnO}$ thin films and show only slight variation at the two different processing temperatures. ${ }^{31}$

Table 1 A summary of the binding energies (eV), FWHM and compositions (\%) for the $\mathrm{Zn} 2 \mathrm{p}$ and $\mathrm{O} 1 \mathrm{~s}$ contributions shown in Fig. 1. $\mathrm{Zn}$ : O ratios are calculated using the Schofield relative sensitivity factors which are built in to CasaXPS, and an analyser transmission function calculated from poly $\mathrm{Ag}, \mathrm{Cu}$ and $\mathrm{Au}$ foils

\begin{tabular}{|c|c|c|c|c|c|c|}
\hline & $\mathrm{eV}$ & $\begin{array}{l}120^{\circ} \mathrm{C} \\
\text { FWHM }\end{array}$ & $\%$ & $\mathrm{eV}$ & $\begin{array}{l}160{ }^{\circ} \mathrm{C} \\
\text { FWHM }\end{array}$ & $\%$ \\
\hline $\mathrm{Zn} 2 \mathrm{p}_{3 / 2}$ & 1020.80 & 1.541 & 28.59 & 1020.79 & 1.532 & 28.98 \\
\hline $\mathrm{Zn} 2 \mathrm{p}_{1 / 2}$ & 1043.99 & 1.599 & 27.86 & 1043.89 & 1.584 & 29.25 \\
\hline $\mathrm{O} 1 \mathrm{~s}_{\mathrm{A}}$ & 529.38 & 1.086 & 13.92 & 529.42 & 1.158 & 18.75 \\
\hline $\mathrm{O} 1 \mathrm{~s}_{\mathrm{B}}$ & 530.77 & 1.853 & 29.62 & 530.88 & 1.794 & 23.02 \\
\hline $\mathrm{Zn} 2 \mathrm{p}_{3 / 2}: \mathrm{O} 1 \mathrm{~s}_{\mathrm{A}}$ & & & $1: 0.49$ & & & $1: 0.64$ \\
\hline $\mathrm{Zn} 2 \mathrm{p}_{3 / 2}: \mathrm{O} 1 \mathrm{~s}_{\mathrm{B}}$ & & & $1: 1.42$ & & & $1: 0.96$ \\
\hline
\end{tabular}



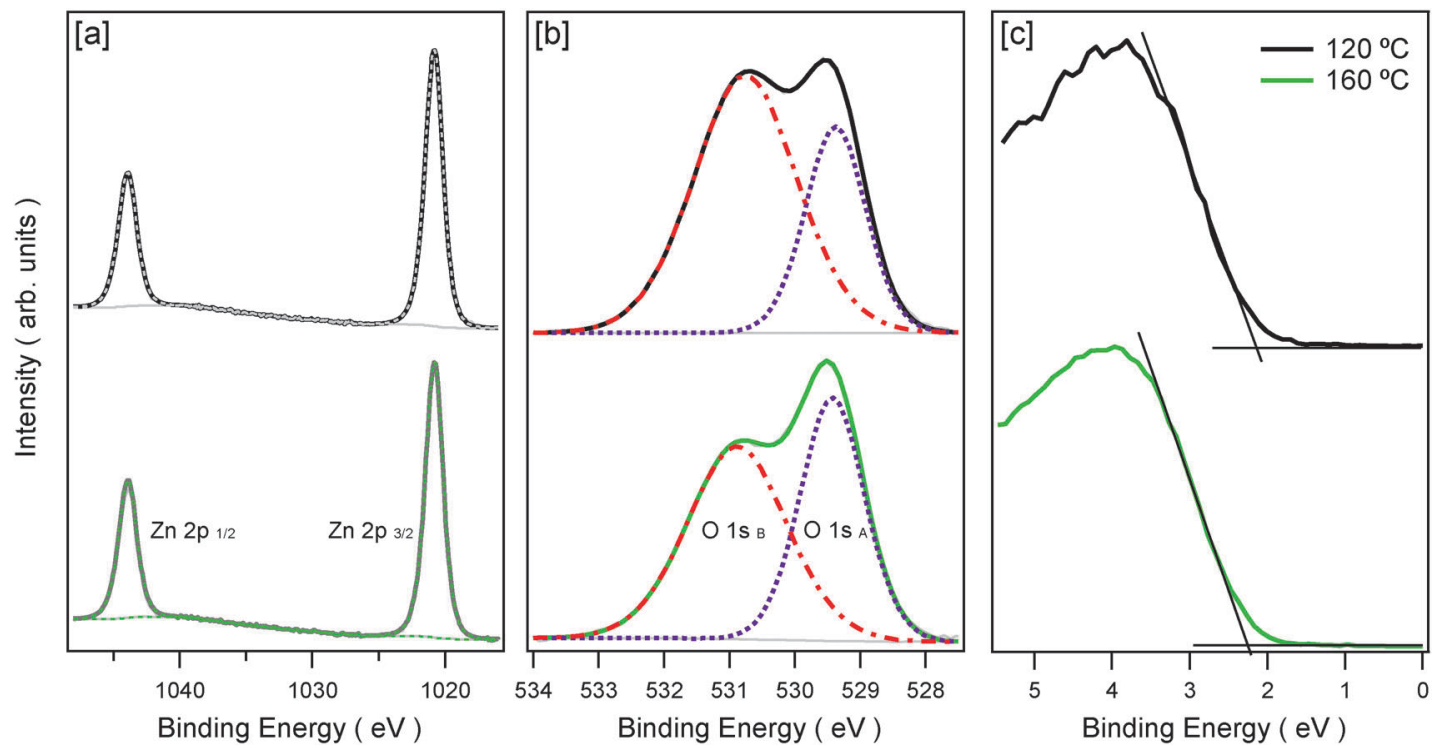

Fig. 3 XPS spectra of [a] $\mathrm{Zn} \mathrm{2p}$, [b] O 1s and [c] the valence band (VB) onset for $\mathrm{ZnO}_{120^{\circ} \mathrm{C}}$ (black solid line) and $\mathrm{ZnO}{ }_{160^{\circ} \mathrm{C}}(\mathrm{green}$ solid line). The $\mathrm{Zn}$ region contains two peaks, $Z n 2 p_{3 / 2}$ and $Z n 2 p_{1 / 2}$, in a $2: 1$ ratio owing to spin-orbit splitting. For $O 1 s$, two components are present, $O 1 s_{A}$ (bound $Z n O$ in a wurtzite lattice) and $\mathrm{O} 1 \mathrm{~s}_{\mathrm{B}}$ (contaminants present). The $\mathrm{VB}$ onset is calculated by the intercept with the binding energy axis.

To gain insight into the influence of processing temperature on ZnO composition, the films were characterised using XPS. Full spectra, including survey scans, are shown in the SI and the data is summarised in Table $1 . \mathrm{Zn}: \mathrm{O}$ ratios are calculated using the Schofield relative sensitivity factors, which are built into CasaXPS, and an analyser transmission function calculated from polycrystalline $\mathrm{Ag}, \mathrm{Cu}$ and $\mathrm{Au}$ foils. In Fig. 3[a], the $\mathrm{Zn} \mathrm{2p}$ peaks are shown for $\mathrm{ZnO}_{120^{\circ} \mathrm{C}}$ and $\mathrm{ZnO}_{160^{\circ} \mathrm{C}}$, with two peaks observed, $2 \mathrm{p}_{3 / 2}(1020.8 \mathrm{eV})$ and $2 \mathrm{p}_{1 / 2}(1043.9 \mathrm{eV})$ in a $2: 1$ ratio due to spin-orbit splitting. Fig. 3[b], shows the comparative study of the core $\mathrm{O} 1 \mathrm{~s}$ region, which comprises two unique components, a wurtzite lattice component with zinc coordinated to oxygen $\left(\mathrm{O} 1 \mathrm{~s}_{\mathrm{A}}, 529.4 \mathrm{eV}\right)$, and a broad $\mathrm{O} 1 \mathrm{~s}$ feature $\left(\mathrm{O} 1 \mathrm{~s}_{\mathrm{B}}, 530.8 \mathrm{eV}\right)$ which can be attributed to contaminants. The full width at half-maximum (FWHM) of the two components differs, being $1.9 \mathrm{eV}$ and $1.85 \mathrm{eV}$ for $\mathrm{O} 1 \mathrm{~s}_{\mathrm{A}}$ and $\mathrm{O} 1 \mathrm{~s}_{\mathrm{B}}$ respectively, due to the difference in bonding environment, with a narrow peak as a result of coordination to the $\mathrm{Zn}$ atom. The contaminants present in $\mathrm{O} 1 \mathrm{~s}_{\mathrm{B}}$ can be firstly attributed to surface adsorbates which are a significant feature due to the surface sensitivity of XPS, but also to materials present in the sol-gel process; $\mathrm{COH}$ from the ethanolamine stabiliser and $\mathrm{COO}^{-}$which can be identified as the oxygen present in the zinc acetate raw material. It is a combination of materials adsorbed on the surface and starting materials trapped in the film that result in the larger FWHM. When comparing the ratio of $\mathrm{Zn}: \mathrm{O}$ $1 \mathrm{~s}_{\mathrm{B}}$ at the two processing temperatures, there is a significant reduction in the contaminants due to the removal of the raw materials, resulting in a decrease in the ratio from $1: 1.41$ $\left(\mathrm{ZnO}_{120^{\circ} \mathrm{C}}\right)$ to $1: 0.96\left(\mathrm{ZnO}_{160^{\circ} \mathrm{C}}\right)$.

The impact of defects in terms of the effect on carrier concentration and work function is still widely debated. In a recent paper by Greiner $e t$ al. it was reported that a change in cationic oxidation state can result in a significant change in the work function of the TMO layer. ${ }^{32}$ This in turn could have an effect on the capability of the metal oxide to work as an electron acceptor due to the impact on the level of the CB and VB with respect to the vacuum level $V_{\mathrm{L}}$, and in turn the organic donor material. By increasing the processing temperature by $40{ }^{\circ} \mathrm{C}$, there is a change in the stoichiometry of the $\mathrm{ZnO}$ films with a $\mathrm{Zn} 2 \mathrm{p}_{3 / 2}: \mathrm{O} 1 \mathrm{~s}_{\mathrm{A}}$ ratio of $1: 0.49$ for $\mathrm{ZnO}_{120^{\circ} \mathrm{C}}$ to $1: 0.64$ for $\mathrm{ZnO}_{160^{\circ} \mathrm{C}}$. This suggests that the increase in temperature leads to an increase in the conversion to zinc oxide, which may alter the work function of these layers.

KP measurements were carried out to determine the work function of the two ZnO films. There is a significant difference in the work function of the layers, from $3.2 \mathrm{eV}$ to $3.8 \mathrm{eV}$ for $\mathrm{ZnO}_{120^{\circ} \mathrm{C}}$ and $\mathrm{ZnO}_{160^{\circ} \mathrm{C}}$ respectively. The VB edge XPS spectra for the two ZnO films are shown in Fig. $3[\mathrm{c}]$ and provide further understanding of the electronic properties. The position of the surface Fermi level $\left(E_{\mathrm{Fs}}\right)$ was determined by extrapolating the leading edge of the VB photoemission to the intercept with the background level. The $E_{\mathrm{Fs}}$ for $\mathrm{ZnO}_{120^{\circ} \mathrm{C}}$ is $2.20 \mathrm{eV}$ above the $\mathrm{VB}$, giving a $\mathrm{VB}$ position of $5.40 \mathrm{eV}$ below the $V_{\mathrm{L}}$. In the case of $\mathrm{ZnO}_{160^{\circ} \mathrm{C}}$, which has a similar $E_{\mathrm{Fs}}$ of $2.25 \mathrm{eV}$, the film has a much deeper VB position of $6.05 \mathrm{eV}$ below the $V_{\mathrm{L}}$ owing to the larger measured work function. These results are summarised in Fig. 4, with the positions of the $\mathrm{CB}$ estimated from the optical band gap (Fig. 1).

By sequentially depositing thin layers of the SubPc onto the ZnO surface further information can be gained about the electronic properties of the donor/acceptor interface. It is key to note here that unlike the small interfacial dipoles formed at an organic-organic interface, large $V_{\mathrm{L}}$ shifts would be expected for an inorganic-organic interface. Therefore, measurements indicating the energy level offsets in this region are essential for 

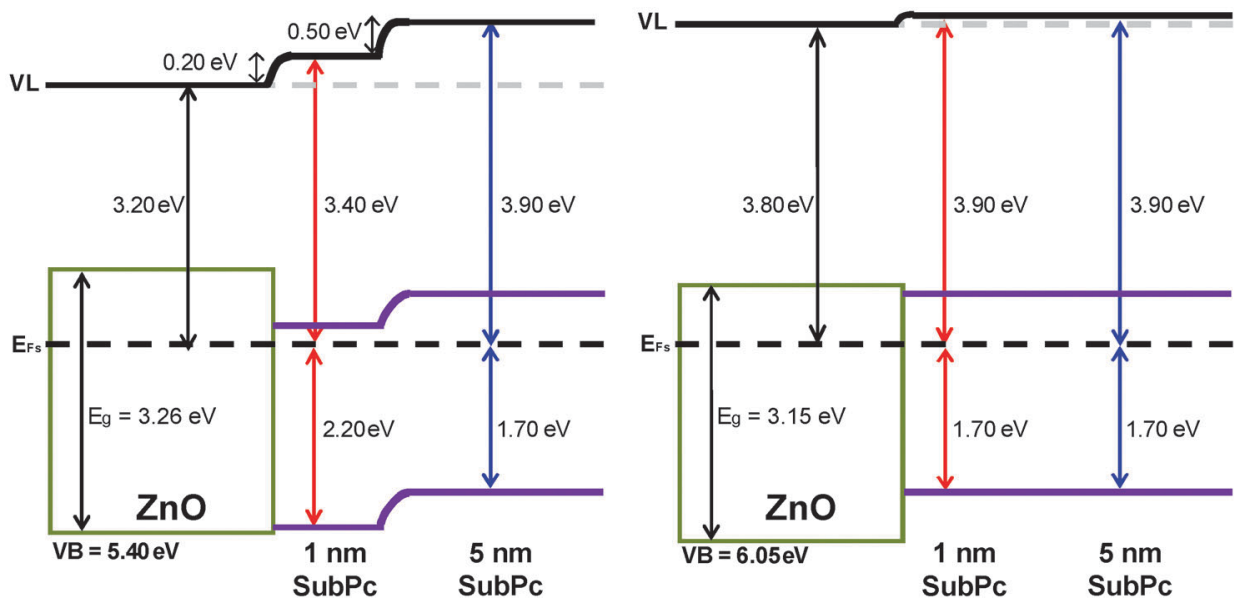

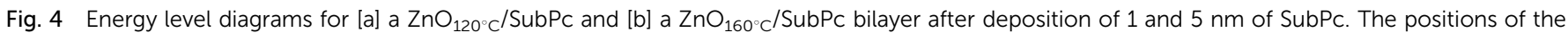
surface Fermi level $\left(E_{\mathrm{Fs}}\right)$ and both the valence and conduction bands of the ZnO layers were determined by KP, XPS and UV-vis respectively.

understanding device parameters. ${ }^{33,34}$ Fig. 4 indicates the change in work function with subsequent growth of SubPc. For $\mathrm{ZnO}_{120^{\circ} \mathrm{C}}$ the work function is increased from $3.2 \mathrm{eV}$ to $3.4 \mathrm{eV}$ with the addition of $1 \mathrm{~nm}$ SubPc, resulting in a vacuum level shift of $0.20 \mathrm{eV}$. The work function increases further to $3.90 \mathrm{eV}$ for a $5 \mathrm{~nm}$ SubPc layer. With deposition on $\mathrm{ZnO}_{160^{\circ} \mathrm{C}}$ there is only a subtle change in work function from $3.80 \mathrm{eV}$ to $3.90 \mathrm{eV}$, and a small resultant vacuum level shift, for both the 1 and $5 \mathrm{~nm}$ thicknesses of the SubPc. This work function saturates past $5 \mathrm{~nm}$ of SubPc, and remains constant at $15 \mathrm{~nm}$ for both the $\mathrm{ZnO}$ films.

The position of the HOMO level of SubPc is included in Fig. 4, which is calculated by assuming an ionisation potential (IP) for SubPc of $5.60 \mathrm{eV} .^{35,36}$ For organic/organic heterojunctions the $I_{\mathrm{g}}$ of the donor/acceptor interface is known to directly influence $V_{\text {OC }}$. If the same principle is used here, the maximum obtainable $V_{\mathrm{OC}}$ can be estimated from the difference between the $\mathrm{HOMO}_{\mathrm{SubPc}}$ and $E_{\mathrm{Fs}}$. This estimation is made due to the n-type nature of $\mathrm{ZnO}$ thin films and the presence of gap states that have been shown to lie close to the $E_{\mathrm{Fs}}$ of the material and can extract electrons. ${ }^{37}$ Band bending in the near interfacial region of the organic $(<5 \mathrm{~nm}$ ) would be expected to provide an additional driving force for photocurrent extraction, and hence a larger expected $V_{\text {OC }}$. Thus, the interfacial region is of more significance than the bulk $(>5 \mathrm{~nm}$ ) collection levels of the organic. Consequently, if the difference in HOMO onsets with a $1 \mathrm{~nm}$ SubPc layer is considered, the value decreases from $2.20 \mathrm{eV}\left(\mathrm{ZnO}_{120^{\circ} \mathrm{C}}\right)$ to $1.70 \mathrm{eV}\left(\mathrm{ZnO}_{160^{\circ} \mathrm{C}}\right)$, and a difference in $V_{\mathrm{OC}}$ would be expected.

Table 2 Averaged HOPV device characteristics for the hybrid devices: $\mathrm{ITO} / \mathrm{ZnO}_{\left(120^{\circ} \mathrm{Cor} 160^{\circ} \mathrm{C}\right)} / \mathrm{SubPc}(15 \mathrm{~nm}) / \mathrm{MoO}_{x}(15 \mathrm{~nm}) / \mathrm{Al}$. The standard deviation for each parameter is shown in brackets

\begin{tabular}{lllll}
\hline Temp $\left({ }^{\circ} \mathrm{C}\right)$ & $J_{\text {SC }}\left(\mathrm{mA} \mathrm{cm}{ }^{-2}\right)$ & $V_{\mathrm{OC}}(\mathrm{V})$ & FF & PCE $(\%)$ \\
\hline $\mathrm{ZnO}_{120}{ }^{\circ} \mathrm{C}$ & $1.63(0.10)$ & $1.18(0.09)$ & $0.25(0.03)$ & $0.47(0.05)$ \\
$\mathrm{ZnO}_{160^{\circ} \mathrm{C}}$ & $1.66(0.14)$ & $0.82(0.10)$ & $0.29(0.01)$ & $0.39(0.07)$
\end{tabular}
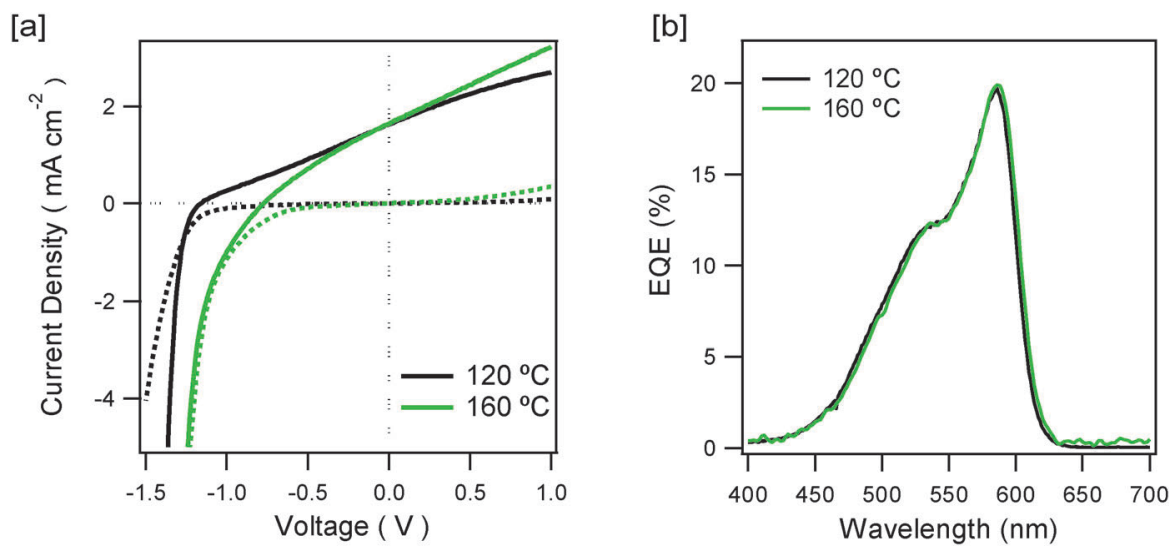

Fig. 5 Averaged current density-voltage plots under illumination of $100 \mathrm{~mW} \mathrm{~cm}^{-1}$ for the $\mathrm{ZnO} / \mathrm{SubPc} \mathrm{HOPV}_{\text {devices with } \mathrm{ZnO}} \mathrm{ZnO}^{\circ} \mathrm{C}(\mathrm{black}$ solid line) and $\mathrm{ZnO}_{160^{\circ} \mathrm{C}}$ (green solid line). The corresponding dark current density-voltage plots are shown as dotted lines. [b] EQE of a representative pixel for $\mathrm{ZnO} \mathrm{B}_{120^{\circ} \mathrm{C}}$ (black solid line) and $\mathrm{ZnO}_{160^{\circ} \mathrm{C}}$ (green solid line). 
To validate this hypothesis, bilayer HOPV cells were fabricated with the architecture: ITO/ZnO (45 nm)/SubPc (15 nm)/ $\mathrm{MoO}_{x}(15 \mathrm{~nm}) / \mathrm{Al}$. Key device parameters are shown in Table 2 with the corresponding $J-V$ plots in Fig. 5[a]. The thickness of the SubPc layer was kept constant at $15 \mathrm{~nm}$ as it is consistent with previously published exciton diffusion lengths for the material. ${ }^{38,39}$ As predicted there is a significant improvement in $V_{\mathrm{OC}}$ from $0.82 \mathrm{~V}$ for $\mathrm{ZnO}_{160^{\circ} \mathrm{C}}$ to $1.18 \mathrm{~V}$ for $\mathrm{ZnO}_{120^{\circ} \mathrm{C}}$, demonstrating clearly the significance the increase in $I_{\mathrm{g}}$ has on the achievable $V_{\text {OC }}$ for these hybrid devices. Another factor contributing to the difference in $V_{\mathrm{OC}}$ could be the suppression in dark current due to lower mobility of the films. However this affect is likely to be more of a secondary causation.

The voltage achieved for this cell is very high for a single junction cell and shows the potential of organic donors to be utilised with TMO acceptors for high performance. The enhanced $I_{\mathrm{g}}$, along with the high IP SubPc donor results in higher $V_{\mathrm{OC}}$ values than obtained with polymeric alternatives such as P3HT, which typically yield values less than $0.7 \mathrm{~V}^{23}$ There is approximately a $1 \mathrm{eV}$ difference between the predicted $I_{\mathrm{g}}$ and the measured $V_{\mathrm{OC}}$ of the device, which is not uncommon for excitonic solar cells due to the losses associated such as the exciton binding energy, recombination of charge transfer states and the diffusion of charge carriers to the electrodes. ${ }^{40}$ Also owing to the nature of the $\mathrm{ZnO}$ film and the fact that there are likely to be gap states near to/around the $E_{\mathrm{Fs}}$ it is difficult to pinpoint the exact energy at which charges will be extracted.

The thin $\mathrm{ZnO}$ electron accepting layer, owing to its wide optical band gap, has high transparency across the entire visible range, so does not contribute to the photocurrent during device operation. This is shown in Fig. 5[b] which shows the EQE of the two device architectures, showing only the SubPc film contributes to the current of the device. Despite only one current contributor, the optimised $\mathrm{ZnO} / \mathrm{SubPc}$ hybrid devices gave a relatively high $J_{\mathrm{SC}}$ of $>1.5 \mathrm{~mA} \mathrm{~cm} \mathrm{~cm}^{-2}$, outperforming other TMO/small molecule hybrid devices where the best published value for $J_{\mathrm{SC}}$ currently stands at $0.015 \mathrm{~mA} \mathrm{~cm}{ }^{-2}{ }^{26}$ This indicates that $\mathrm{ZnO}_{120^{\circ} \mathrm{C}}$ and $\mathrm{ZnO}_{160^{\circ} \mathrm{C}}$ are both efficient at splitting excitons at the interface with SubPc. The main limitation of the devices is the low fill factors (FF) of 0.25 and 0.29 for $\mathrm{ZnO}_{120^{\circ} \mathrm{C}}$ and $\mathrm{ZnO}_{160^{\circ} \mathrm{C}}$ respectively, and this is likely to be due to a photoconductivity effect in the layer, with shunts being exposed when scanning. Despite a $6 \mathrm{~V}$ bias being applied during the C-AFM measurements there is a poor averaged surface current of $63 \mathrm{pA}$ for $\mathrm{ZnO}_{120^{\circ} \mathrm{C}}$ which can be seen in Fig. 1[c]. The average current is greatly improved to $1.2 \mathrm{nA}$ for $\mathrm{ZnO}_{160^{\circ} \mathrm{C}}$ (Fig. 1[d]) which in turn explains the improvement in FF to 0.29 . This is likely to be due to removal of impurities and adsorbates on the surface at the higher annealing temperature (seen by XPS), improving the surface conductivity and resistance. Despite the low FF, the PCE of the devices increases from $0.39 \%\left(\mathrm{ZnO}_{160^{\circ} \mathrm{C}}\right)$ to $0.47 \%\left(\mathrm{ZnO}_{120^{\circ} \mathrm{C}}\right)$ merely by a $40{ }^{\circ} \mathrm{C}$ decrease in the $\mathrm{ZnO}$ processing temperature, with the improvement primarily attributed to the increase in $V_{\text {OC }}$. The voltage exceeds that of $\mathrm{SubPc} / \mathrm{C}_{60}$ devices, which are reported at approximately $1.05 \mathrm{~V},{ }^{36}$ showing the potential of $\mathrm{ZnO}$ as a low temperature, cheap scalable alternative to $\mathrm{C}_{60}$ for use in bilayer HOPV cells.

\section{Conclusions}

We have demonstrated that ZnO films fabricated using the solgel process can be incorporated in bilayer HOPV devices with a small molecule organic donor layer. The effect of processing temperature on the characteristics of the $\mathrm{ZnO}$ layer was investigated using C-AFM, UV-Vis absorption, XPS and KP measurements and revealed an increase in the ratio of the $\mathrm{ZnO} 2 \mathrm{p}_{3 / 2}: \mathrm{O}$ $1 \mathrm{~s}_{\mathrm{A}}$ as the processing temperature was decreased from $160{ }^{\circ} \mathrm{C}$ to $120^{\circ} \mathrm{C}$. This change in stoichiometric ratio resulted in a decrease in the work function of the layer, but an increase in the overall $I_{\mathrm{g}}$. HOPV devices showed an increase in $V_{\text {OC }}$ of $0.36 \mathrm{~V}$, from $0.82 \mathrm{~V}$ to $1.18 \mathrm{~V}$, a consequence of the increased $I_{\mathrm{g}}$. The results demonstrate that $\mathrm{ZnO}$ can be used as an electron acceptor in small molecule hybrid planar bilayer cells achieving a very respectable PCE of $0.47 \%$, two orders of magnitude larger than previously reported small molecule hybrid cells, and with a remarkably high $V_{\text {OC }}$ of $1.18 \mathrm{~V}$.

\section{Funding sources}

This work was supported by the Engineering and Physical Sciences Research Council (grant number EP/J500057/1). The Science City XPS system used in this research was funded through the Science Cities Advanced Materials Project 1: Creating and Characterising Next Generation of Advanced Materials with support from AWM and ERDF funds.

\section{References}

1 S. Holger and F. C. Krebs, Sol. Energy Mater. Sol. Cells, 2004, 83, 125.

2 A. Hübler, B. Trnovec, T. Zillger, M. Ali, N. Wetzold, M. Mingebach, A. Wagenpfahl, C. Deibel and V. Dyakonov, Adv. Energy Mater., 2011, 1, 1018-1022.

3 N. K. Unsworth, I. Hancox, C. Argent Dearden, T. Howells, P. Sullivan, R. S. Lilley, J. Sharp and T. S. Jones, Appl. Phys. Lett., 2013, 103, 173304.

4 A. A. Letailleur, F. Ribot, C. Boissière, J. Teisseire, E. Barthel, B. Desmazières, N. Chemin and C. Sanchez, Chem. Mater., 2011, 23, 5082-5089.

5 M. Riede, T. Mueller, W. Tress, R. Schueppel and K. Leo, Nanotechnology, 2008, 19, 424001.

6 Heliatek, Heliatek consolidates its technology leadership by establishing a new world record for organic solar technology with a cell efficiency of 12\%, Accessed June 5th, 2013.

7 S. Schumann, R. Da Campo, B. Illy, A. C. Cruickshank, M. A. McLachlan, M. P. Ryan, D. J. Riley, D. W. McComb and T. S. Jones, J. Mater. Chem., 2011, 21, 2381-2386.

8 E. M. Kaidashev, M. Lorenz, H. v. Wenckstern, A. Rahm, H.-C. Semmelhack, K.-H. Han, G. Benndorf, C. Bundesmann, 
H. Hochmuth and M. Grundmann, Appl. Phys. Lett., 2003, 82, 3901-3903.

9 A. M. Peiro, P. Ravirajan, K. Govender, D. S. Boyle, P. O'Brien, D. D. C. Bradley, J. Nelson and J. R. Durrant, J. Mater. Chem., 2006, 16, 2088-2096.

10 G. Adamopoulos, A. Bashir, W. P. Gillin, S. Georgakopoulos, M. Shkunov, M. A. Baklar, N. Stingelin, D. D. C. Bradley and T. D. Anthopoulos, Adv. Funct. Mater., 2011, 21, 525-531.

11 Y. Sun, J. H. Seo, C. J. Takacs, J. Seifter and A. J. Heeger, Adv. Mater., 2011, 23, 1679-1683.

12 S. T. Meyers, J. T. Anderson, C. M. Hung, J. Thompson, J. F. Wager and D. A. Keszler, J. Am. Chem. Soc., 2008, 130, 17603-17609.

13 Y.-B. Hahn, Korean J. Chem. Eng., 2011, 28, 1797-1813.

14 S. K. Hau, H.-L. Yip, N. S. Baek, J. Zou, K. O'Malley and A. K.-Y. Jen, Appl. Phys. Lett., 2008, 92, 253301.

15 J. Huang, Z. Yin and Q. Zheng, Energy Environ. Sci., 2011, 4, 3861-3877.

16 S. D. Oosterhout, M. M. Wienk, S. S. van Bavel, R. Thiedmann, L. Jan Anton Koster, J. Gilot, J. Loos, V. Schmidt and R. A. J. Janssen, Nat. Mater., 2009, 8, 818-824.

17 W. J. Potscavage, S. Yoo and B. Kippelen, Appl. Phys. Lett., 2008, 93, 193308.

18 R. A. Marsh, C. Groves and N. C. Greenham, J. Appl. Phys., 2007, 101, 083509.

19 A. Gadisa, M. Svensson, M. R. Andersson and O. Inganäs, Appl. Phys. Lett., 2004, 84, 1609-1611.

20 T. Ishwara, D. D. C. Bradley, J. Nelson, P. Ravirajan, I. Vanseveren, T. Cleij, D. Vanderzande, L. Lutsen, S. Tierney, M. Heeney and I. McCulloch, Appl. Phys. Lett., 2008, 92, 053308.

21 P. Peumans and S. R. Forrest, Appl. Phys. Lett., 2001, 79, 126-128.

22 A. Wilke, J. Endres, U. Hörmann, J. Niederhausen, R. Schlesinger, J. Frisch, P. Amsalem, J. Wagner, M. Gruber, A. Opitz, A. Vollmer, W. Brütting, A. Kahn and N. Koch, Appl. Phys. Lett., 2012, 101, 233301.
23 S. R. Ferreira, R. J. Davis, Y.-j. Lee, P. Lu and J. W. P. Hsu, Org. Electron., 2011, 12, 1258-1263.

24 G. D. Sharma, R. Kumar, S. K. Sharma and M. S. Roy, Sol. Energy Mater. Sol. Cells, 2006, 90, 933-943.

25 L. Shen, G. H. Zhu, W. B. Guo, C. Tao, X. D. Zhang, C. X. Liu, W. Y. Chen, S. P. Ruan and Z. C. Zhong, Appl. Phys. Lett., 2008, 92, 073307.

26 M. Izaki, R. Chizaki, T. Saito, K. Murata, J. Sasano and T. Shinagawa, ACS Appl. Mater. Interfaces, 2013, 5, 9386-9395.

27 H. Fritzsche, J. Non-Cryst. Solids, 1971, 6, 49-71.

28 M. C. Gwinner, R. D. Pietro, Y. Vaynzof, K. J. Greenberg, P. K. H. Ho, R. H. Friend and H. Sirringhaus, Adv. Funct. Mater., 2011, 21, 1432-1441.

29 M. C. Biesinger, L. W. M. Lau, A. R. Gerson and R. S. C. Smart, Appl. Surf. Sci., 2010, 257, 887-898.

30 J. Fryar, E. McGlynn, M. O. Henry, A. A. Cafolla and C. J. Hanson, Nanotechnology, 2004, 15, 1797.

31 U. Ozgur, Y. I. Alivov, C. Liu, A. Teke, M. A. Reshchikov, S. Dogan, V. Avrutin, S.-J. Cho and H. Morkoc, J. Appl. Phys., 2005, 98, 041301.

32 M. T. Greiner, L. Chai, M. G. Helander, W.-M. Tang and Z.-H. Lu, Adv. Funct. Mater., 2012, 22, 4557-4568.

33 H. Ishii, K. Sugiyama, E. Ito and K. Seki, Adv. Mater., 1999, 11, 605-625.

34 N. Beaumont, S. W. Cho, P. Sullivan, D. Newby, K. E. Smith and T. S. Jones, Adv. Funct. Mater., 2012, 22, 561-566.

35 K. L. Mutolo, E. I. Mayo, B. P. Rand, S. R. Forrest and M. E. Thompson, J. Am. Chem. Soc., 2006, 128, 8108-8109.

36 I. Hancox, L. A. Rochford, D. Clare, P. Sullivan and T. S. Jones, Appl. Phys. Lett., 2011, 99, 013304.

37 L. Schmidt-Mende and J. L. MacManus-Driscoll, Mater. Today, 2007, 10, 40-48.

38 H. Gommans, S. Schols, A. Kadashchuk, P. Heremans and S. C. J. Meskers, J. Phys. Chem. C, 2009, 113, 2974-2979.

39 R. R. Lunt, N. C. Giebink, A. A. Belak, J. B. Benziger and S. R. Forrest, J. Appl. Phys., 2009, 105, 053711.

40 D. Veldman, S. C. J. Meskers and R. A. J. Janssen, Adv. Funct. Mater., 2009, 19, 1939-1948. 